\title{
Differential effects of preterm birth and small gestational age on cognitive and motor development
}

\author{
Jane L Hutton, Peter O D Pharoah, Richard W I Cooke, Richard C Stevenson
}

The University of

Liverpool,

Department of Public

Health

POD Pharoah

Department of

Statistics and

Computational

Mathematics

JL Hutton

Department of Child Health

RWI Cooke

Department of Economics and Business Studies RC Stevenson

Correspondence to: Professor Pharoah, Department of Public Health,

University of Liverpool,

Liverpool, L69 3BX.

Accepted 11 October 1996

\begin{abstract}
Aims-To determine the differential effects of preterm birth and being small for gestational age on the cognitive and motor ability of the child.

Methods-A longitudinal cohort of all infants of gestational age $\leq \mathbf{3 2}$ weeks born to mothers resident in the counties of Cheshire and Merseyside in 1980-1 was studied. The children were assessed at the age of 8 to 9 years using the Wechsler Intelligence Scale for Children, the Neale analysis of reading ability, and the StottMoyes-Henderson test of motor impairment. Adequacy of fetal growth was determined by the birthweight ratio-that is, the ratio of the observed birthweight to the expected birthweight for a given gestational age. Children with clinically diagnosed motor, learning or sensory disabilities were excluded. Information on social variables was obtained by a questionnaire completed by the parents. Of the 182 children, 158 were assessed.

Results-IQ was positively correlated with birthweight ratio but not with birthweight or gestational age. Motor ability was associated with birthweight, gestational age, and birthweight ratio. Reading comprehension was associated with birthweight ratio, but reading rate and accuracy were best explained by social variables and sex. IQ remained associated with birthweight ratio, after adjusting for maternal education, housing status, and number of social service benefits received. Reading ability was related to these social variables but motor ability was not.

Conclusions-The effects of SGA and preterm birth differed: SGA was associated with cognitive ability, as measured by IQ and reading comprehension; motor ability was additionally associated with preterm birth. Reading rate and accuracy were not associated with SGA or preterm birth but were socially determined.

(Arch Dis Child 1997;76:F75-F81)
\end{abstract}

Keywords: cognitive ability; motor development; small for gestational age; social factors.

Being small for gestational age (SGA) is associated with a variety of adverse outcomes, including impaired performance over a wide range of cognitive and sensorimotor functions. ${ }^{1-8}$ SGA may be due to an inherent abnormality of the fetus, such as a chromosomal or other congenital abnormality, or it may be the result of maternal disease and placental insufficiency. ${ }^{1011}$ Much of the information on the adverse effects of SGA relates to growth retardation in late gestation or in the full term infant. Less is known about growth retardation that has occurred earlier in gestation. The effects of early and late growth retardation may differ because the term growth retarded infant may have experienced the adverse intrauterine environment for longer than the premature growth retarded infant, or the same adverse circumstance may have a different effect depending on the stage of organ development at the time of exposure. Alternatively, more intense exposure to an adverse factor may result in growth retardation and precipitate premature labour, while less intense exposure may lead only to growth retardation. A hypothetical example could be maternal preeclampsia, in which mild pre-eclampsia might lead to fetal growth retardation, but more severe eclampsia might result in premature delivery and fetal growth retardation.

Patterns of survival in low birthweight infants have changed sharply in recent years. The neonatal mortality in infants weighing under $1500 \mathrm{~g}$ has fallen from 564 per 1000 live births in 1971 to 211 per 1000 live births in $1991 .{ }^{12} 13$ In particular, infants that are both SGA and preterm, would have died previously, but now, they often survive. The assumption is often that the effects of low birthweight are primarily due to immaturity rather than to SGA. We report here the differential effects of preterm birth and SGA on measures of cognitive and motor function in a geographically defined cohort of infants of gestational age $\leq 32$ weeks.

\section{Methods}

The cohort comprised all infants weighing $\leq$ $2000 \mathrm{~g}$ at birth, born in 1980 and 1981 to mothers resident in the county of Merseyside. They were assessed when they were aged 8 or 9 years. The analysis was limited to those infants whose gestational age at birth had been 32 weeks or less. This gestational age cutoff was made on the assumption that the sample would include all infants of $\leq 32$ weeks gestation and that no infant would be excluded by the birthweight limit of $2000 \mathrm{~g}$. The estimate of gestational age was based on information in the hospital case records on the date of the mother's last menstrual period and clinical assess- 
Table 1 Characteristics of 182 children of birthweight $<2 \mathrm{~kg}$ and gestational age $\leq 32$ weeks

\begin{tabular}{|c|c|c|c|c|c|c|c|}
\hline \multirow[b]{2}{*}{ Characteristic } & \multirow[b]{2}{*}{ Category } & \multicolumn{2}{|c|}{ Tested } & \multicolumn{2}{|c|}{ Not tested } & \multicolumn{2}{|c|}{ Refused } \\
\hline & & No & $(\%)$ & No & $(\%)$ & No & $(\%)$ \\
\hline \multirow[t]{2}{*}{ Sex } & Female & 71 & 45 & 8 & 53 & 4 & 44 \\
\hline & Male & 87 & 55 & 7 & 47 & 5 & 56 \\
\hline \multirow[t]{2}{*}{ Plurality } & Singleton & 129 & 82 & 12 & 80 & 6 & 67 \\
\hline & Twin or triplet & 29 & 18 & 3 & 20 & 3 & 33 \\
\hline \multirow[t]{3}{*}{ TOMI } & $<2$ & 50 & 32 & & & & \\
\hline & $2 \leq \mathrm{TOMI}<4$ & 41 & 26 & & & & \\
\hline & $\geq 4$ & 67 & 42 & 15 & 100 & & \\
\hline \multirow[t]{3}{*}{ Maternal age left education (years) } & $\leq 16$ & 105 & 66 & & & & \\
\hline & $\geq 17$ & 24 & 15 & & & & \\
\hline & Missing & 29 & 18 & 15 & 100 & 9 & 100 \\
\hline \multirow{3}{*}{ Housing } & Owner-occupied & 71 & 45 & & & & \\
\hline & Rented & 63 & 40 & & & & \\
\hline & Missing & 24 & 15 & 15 & 100 & 9 & 100 \\
\hline \multirow{3}{*}{ Number of benefits } & 0 or 1 & 59 & 37 & & & & \\
\hline & $>1$ & 69 & 44 & & & & \\
\hline & Missing & 30 & 19 & 15 & 100 & 9 & 100 \\
\hline \multirow{5}{*}{$\begin{array}{l}\text { Mother: No of cigarettes per day during } \\
\text { pregnancy }\end{array}$} & Nil & 61 & 39 & 5 & 33 & 2 & 22 \\
\hline & $<10$ & 18 & 11 & 1 & 7 & 0 & 0 \\
\hline & $10-19$ & 45 & 28 & 6 & 40 & 5 & 56 \\
\hline & $\geq 20$ & 28 & 18 & 2 & 13 & 0 & 0 \\
\hline & Missing & 6 & 4 & 1 & 7 & 2 & 22 \\
\hline
\end{tabular}

ment. If date of last menstrual period and clinical assessment did not match, the latter was taken as the correct value. Some children with disabilities, such as cerebral palsy or congenital abnormalities, such as Down's syndrome, could not be tested. The measure of SGA or fetal growth retardation was determined by the ratio of actual birthweight to expected birthweight. The expected birthweight was the mean for gestational age, and allowed for sex, parity in two categories (primiparae and multiparae), and plurality of birth in two categories (singleton and twin), using the Scottish national data on 894066 live births between 1985 and $1989 .^{14}$

The Wechsler Intelligence Scale for Children (WISC) 1974 revision (British version) ${ }^{15}$ uses standardised verbal and non-verbal tasks to assess overall intellectual capacity calculated as the intelligence quotient (IQ), which was the ratio of assessed mental age to chronological age times 100 . It measures the ways a child responds to a series of different stimuli which represent different skills used in everyday life. The full IQ determined by the WISC-R can be subcategorised into verbal and performance components.

The Neale analysis of reading ability consists of six passages of prose forming a continuous reading scale for children aged 6 to 13 years. ${ }^{16}$ Eight comprehensive questions to each of the passages except the first, which has only four, allow age norms to be determined. The accuracy, comprehension, and rate of reading were assessed. The score attained in each of these three components was the reading age expressed in months.

The Stott-Moyes-Henderson test of motor impairment (TOMI) was designed as a screening test to determine motor disability in children from the age of 5 years and over. ${ }^{17}$ The tests consist of a series of eight motor tasks which assess manual dexterity, ball skills, and balance. The score (range 0-16) indicates the extent to which a motor impaired child falls below the level of his or her age peers. The total score was a summation of the individual scores for manual dexterity, ball skills, and balance. A score in the range 4.0 to 5.5 suggests a moderate motor problem, and one of 6.0 or more indicates a definite motor problem.

The cognitive and motor assessments were all carried out by two psychologists. One assessed those children born in 1980 and the other assessed children born in 1981. The age at testing was the postnatal age.

Socioeconomic factors are associated with cognitive and motor development. Information on socioeconomic factors was obtained from questionnaires given to the parents who attended their child's assessment, and posted to those who did not attend the assessment. Adequate responses were received on the number of state benefits received, whether recorded as living in owner-occupied housing, and the educational achievements of the mother, and her cigarette consumption during pregnancy. Social class and the income band of the head of household were insufficiently recorded, and could not be used as explanatory variables.

\section{STATISTICAL METHODS}

Linear regression was used to investigate, initially separately, the effects of sex, birthweight, gestational age, birth weight ratio on IQ, reading ability and motor skills. The joint effects on IQ of sex, birthweight, gestational age, birthweight ratio, reading ability and motor skills were then assessed. All subset regressions were carried out, and Mallow's $C_{p}$ calculated. ${ }^{18}$ The models with lowest $\mathrm{C}_{\mathrm{p}}$ were chosen. These choices were checked by repeating all subsets regression with additional random uniform and normal covariates. ${ }^{19}$

The effects of adjusting for socioeconomic status was assessed by calculating the linear regression for the models chosen by the procedure above, in addition to indicator variables showing whether the mother left full time education by the age of 16 , whether she was living in owner-occupied housing, and whether the family received more than one social service benefit. These indicator variables were reduced from more detailed classifications by considering analyses of variance of full IQ and Scheffe's 
Table 2 Characteristics of 182 children of birthweight $<2 \mathrm{~kg} \leq 32$ weeks

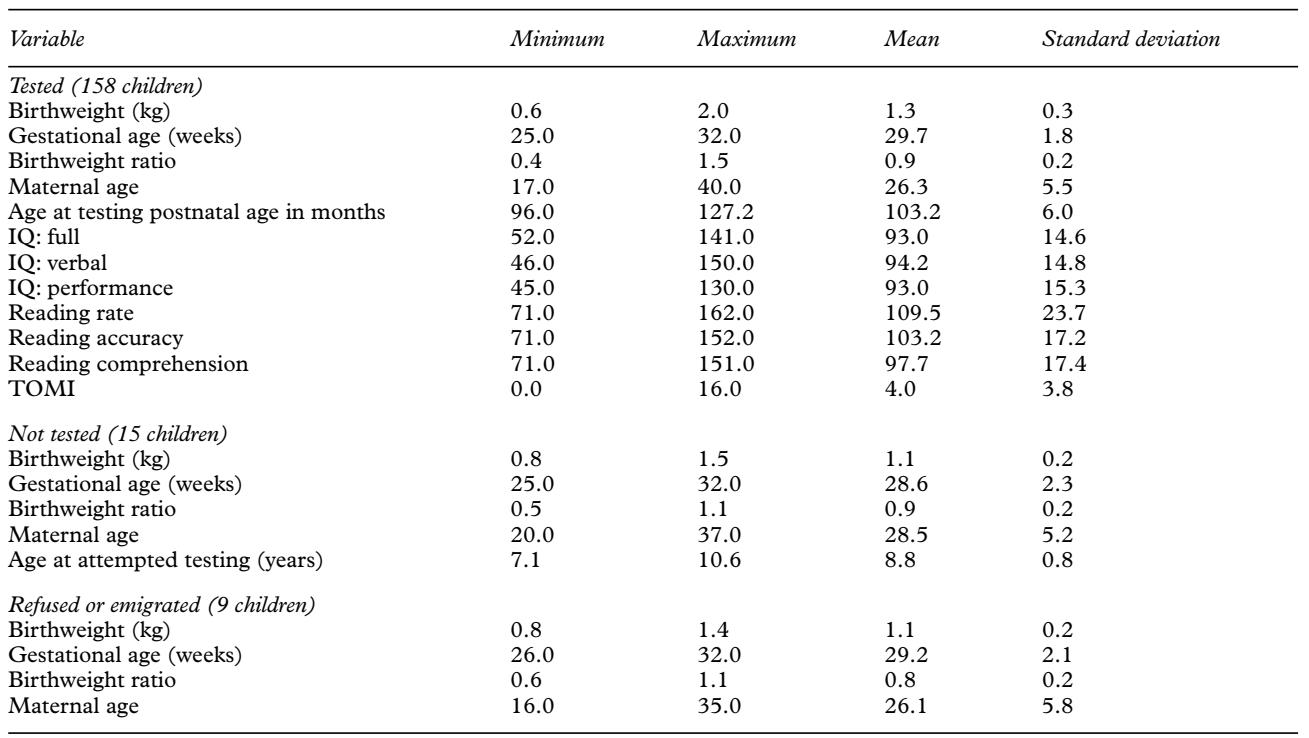

A score of 71 for reading indicates the child was unable to reach the basic level.

Table 3 Linear regression of development on birthweight and gestational age of 158 children: $y=a+b x$

\begin{tabular}{|c|c|c|c|c|c|c|}
\hline \multirow{2}{*}{$\begin{array}{l}\text { Outcome variable } \\
\text { (y) }\end{array}$} & \multirow{2}{*}{$\begin{array}{l}\text { Explanatory variable } \\
(x)\end{array}$} & \multicolumn{2}{|c|}{ Estimated } & \multirow{2}{*}{$\begin{array}{l}\text { Standard Error } \\
\text { of } b\end{array}$} & \multirow[b]{2}{*}{$P$ value for $b$} & \multirow[b]{2}{*}{ Adjusted $100 \times r^{2}$} \\
\hline & & $a$ & $b$ & & & \\
\hline \multirow[t]{3}{*}{ Full $I Q$} & Birthweight & 82.2 & 8.6 & 4.3 & 0.048 & 1.9 \\
\hline & Birthweight ratio & 74.8 & 21.1 & 7.2 & 0.040 & 4.7 \\
\hline & Gestational age & 94.0 & -0.0 & 0.6 & 0.961 & 0.0 \\
\hline \multirow[t]{3}{*}{ Verbal IQ } & Birthweight & 85.6 & 6.8 & 4.4 & 0.125 & 0.9 \\
\hline & Birthweight ratio & 81.9 & 14.2 & 7.4 & 0.058 & 1.7 \\
\hline & Gestational age & 88.8 & 0.2 & 0.7 & 0.782 & 0.0 \\
\hline \multirow[t]{3}{*}{ Performance IQ } & Birthweight & 80.8 & 9.6 & 4.5 & 0.035 & 2.2 \\
\hline & Birthweight ratio & 69.6 & 27.1 & 7.4 & 0.000 & 7.3 \\
\hline & Gestational age & 102.5 & -0.3 & 0.7 & 0.639 & 0.0 \\
\hline \multirow[t]{3}{*}{ TOMI score } & Birthweight & 5.8 & -1.5 & 1.1 & 0.192 & 0.5 \\
\hline & Birthweight ratio & 6.2 & -2.5 & 1.9 & 0.182 & 0.5 \\
\hline & Gestational age & 8.3 & -0.1 & 0.2 & 0.381 & 0.1 \\
\hline \multirow[t]{4}{*}{ Reading rate } & Birthweight & 114.6 & -4.0 & 7.1 & 0.572 & 0.4 \\
\hline & Birthweight ratio & 94.5 & 17.3 & 11.9 & 0.148 & 0.7 \\
\hline & Gestational age & 146.6 & -1.2 & 1.0 & 0.235 & 0.3 \\
\hline & Sex $($ female $=1)$ & 103.3 & 14.6 & 3.6 & 0.000 & 8.8 \\
\hline \multirow[t]{4}{*}{ Accuracy } & Birthweight & 98.3 & 3.9 & 5.2 & 0.451 & 0.0 \\
\hline & Birthweight ratio & 97.1 & 7.1 & 8.7 & 0.415 & 0.0 \\
\hline & Gestational age & 90.2 & 0.4 & 0.8 & 0.566 & 0.0 \\
\hline & Sex $($ Female $=1)$ & 100.4 & 6.3 & 2.7 & 0.022 & 2.7 \\
\hline \multirow[t]{4}{*}{ Comprehension } & Birthweight & 91.2 & 5.1 & 5.2 & 0.326 & 0.0 \\
\hline & Birthweight ratio & 84.5 & 15.2 & 8.7 & 0.081 & 1.3 \\
\hline & Gestational age & 100.6 & -0.1 & 0.8 & 0.900 & 0.0 \\
\hline & Sex $($ Female $=1)$ & 97.4 & 0.7 & 2.8 & 0.802 & 0.0 \\
\hline
\end{tabular}

multiple comparisons procedure ${ }^{20}$; significance comparisons were retained. For each of these, an indicator for missing data was also included, as willingness to give this information was associated with the outcome measures. The effect of maternal smoking during pregnancy was also assessed. Residual plots and Cook's distances ${ }^{21}$ were used to check the assumptions made in using linear regression: linear association between explanatory and outcome variables; errors distributed with constant variance about regression lines; and no individual data points with unduly large influence on the results. The regressions used all children with complete data on the relevant covariates.

\section{Results}

CHARACTERISTICS OF THE GROUP

There were 40321 live births to Merseyside residents in 1980-1, of whom 946 weighed $\leq$ $2000 \mathrm{~g}$ and they formed the initial cohort. All
182 children with a gestational age of $\leq 32$ weeks were eligible for entry into the study. Of these, 158 had their reading ability, TOMI, and IQ assessed; 15 children with several disabilities (11 cerebral palsy, two Down's syndrome, one blind and one with severe epilepsy) could not perform the tests and were excluded; nine children had emigrated or refused to participate. Tables 1 and 2 summarise of the characteristics of these three groups. Of the 158 children tested, $45 \%$ were girls, and one in five was from a twin pregnancy. Those who could not be tested because of disability had high TOMI scores. Five children with cerebral palsy, who were not severely disabled, were tested for IQ and reading, although they had maximum TOMI scores of 16 . The 158 children had a mean gestational age of just less than 30 weeks, and a mean birthweight of 1.3 $\mathrm{kg}$ (table 2). The mean birthweight ratio was 0.9 . The mean age at testing was just over $81 / 2$ 
Table 4 Social status and development: age at which mother left full time education (24 left after age 16 years; 105 left by 16;29 not known)

\begin{tabular}{lllll}
\hline $\begin{array}{l}\text { Assessment } \\
\text { measure }\end{array}$ & Category & Mean & $\begin{array}{l}\text { Standard } \\
\text { deviation }\end{array}$ & P value \\
\hline IQ: & & & & \\
Full & Left $>16$ & 105.7 & 13.5 & \\
& Left $\leq 16$ & 92.4 & 12.9 & \\
Verbal & Missing & 84.9 & 14.4 & 0.0001 \\
& Left $>16$ & 108.5 & 17.0 & \\
Performance & Left $\leq 16$ & 92.7 & 12.2 & \\
& Missing & 87.6 & 14.6 & 0.0001 \\
& Left $>16$ & 102.0 & 14.3 & \\
& Left $\leq 16$ & 93.2 & 13.7 & \\
Reading: & Missing & 84.9 & 19.1 & 0.0002 \\
Rate & & & & \\
& Left $>16$ & 121.6 & 23.7 & \\
Accuracy & Left $\leq 16$ & 109.5 & 22.3 & \\
& Missing & 99.8 & 25.0 & 0.0034 \\
Comprehension & Left $>16$ & 118.1 & 20.0 & \\
& Left $\leq 16$ & 102.0 & 14.3 & \\
& Missing & 95.4 & 17.6 & 0.0001 \\
& Left $>16$ & 113.3 & 23.9 & \\
TOMI: & Left $\leq 16$ & 96.0 & 13.4 & \multirow{2}{*}{0.0001} \\
& Missing & 91.1 & 17.1 & \\
& Left $>16$ & 3.00 & 2.45 & \\
& Left $\leq 16$ & 3.05 & 2.30 & \\
& Missing & 8.16 & 5.78 & 0.0001 \\
\hline
\end{tabular}

years, or 103 months. Those excluded because of disability had a slightly lower mean gestational age and birthweight, but the same birthweight ratio. The characteristics of those who emigrated or refused to participate were similar to those of the children who were tested.

The mental age was determined using test procedures that have been standardised on large numbers of children. When the procedures for assessing intellectual ability were initially developed, the mean IQ was 100 . Since then there has been an upward drift in IQ ${ }^{22}$ but the results cited for the United Kingdom do not permit a precise estimate of the current values for British 8 year olds. However, the study sample reported here showed a mean IQ score of 93 (standard deviation of 15), which is at least half a standard deviation below the population average. The mean reading rate was 110 months; reading accuracy was lower at 103 months and mean comprehension was 98 months. Forty per cent of the tested children had TOMI scores of four or more, indicating at least a moderate motor disability. Two thirds of the mothers are recorded as leaving full time education by the age of 16 . Almost half the children are recorded as living in owneroccupied houses. All mothers are entitled to child benefit; almost half recorded receiving one or more additional social service benefits.

\section{UNIVARIATE ANALYSES}

IQ

Linear regression describes how the outcome variable changes as the covariates change. The percentage of variance explained indicates what percentage of the variance of the outcome variable can be attributed to the effect of covariates. Linear regression models for motor skills, IQ, and reading ability on sex, birthweight, gestational age and birthweight ratio, are given in table 3 . Although only $4.7 \%$ of the variation in the IQ scores was explained by birthweight ratio, the association was signifi- cant $(P=0.04)$. The association between verbal IQ and birthweight ratio was marginal, but for performance IQ was highly significant, and explains $7.3 \%$ of the variation. Birthweight was significantly associated with performance IQ $(\mathrm{P}=0.035)$, and hence full IQ $(\mathrm{P}=0.048)$, but not with verbal IQ. Gestational age and sex had no significant effect on any of the IQ scores.

\section{Reading}

Reading accuracy and comprehension were not associated with birthweight ratio, birthweight, gestational age or sex. The mean reading rate and accuracy for girls were 15 and 6 months more than that of boys, respectively. Reading comprehension showed no sex difference. Birthweight ratio, birthweight or gestational age, even after adjusting for sex, showed no association with any of the three measures of reading ability.

\section{TOMI}

The TOMI score was not associated with these birth characteristics.

Social variables and cognitive and motor ability Information on income of the head of the household was missing for $58 \%$ of the cases, but because it was associated with other sociodemographic variables, was not included in the analysis. Social class information was missing for $34 \%$, and was not used for the same reason. Cognitive ability (IQ and measures of reading ability) was strongly associated with housing, level of maternal education, and the number of social service benefits received.

The mean full IQ of the children of mothers who ceased full-time education aged 16 years or younger was 13.4 points lower than that of infants born to mothers who remained in fulltime education after the age of 16 (table 4), and those for whom educational data were not given had a mean full IQ of 84.9, which was even lower. Performance and verbal IQ showed similar differences in means. Reading scores showed the same ordering of the groups, with a smaller difference between those with less education and those with missing data. The children of mothers who had had more education were ahead of their age for reading rate by 12 months, by 16 months for accuracy, and by 17 months for comprehension. The TOMI scores had the same mean-3.0-for both educational groups, but were significantly higher-8.2-for the group with missing data.

A similar ordering of means in IQ, reading, and TOMI scores was observed for housing (table 5) and number of social service benefits received (table 6), although the mean scores in the owner-occupier families or families receiving one or no social service benefits were lower than for families with mothers who continued education after the age of 16 . This essentially reflects the small number of children (24) with mothers still in education after the age of 16 .

None of the assessment variables was associated with maternal smoking during pregnancy. 
Table 5 Social status and development: housing (71 owner occupied; 63 rented; 24 not known)

\begin{tabular}{lllll}
\hline Assessment measure & Category & Mean & $\begin{array}{l}\text { Standard } \\
\text { deviation }\end{array}$ & P value \\
\hline IQ: & Owner occupied & 100.4 & 12.0 & \\
Full & Rented & 88.8 & 12.0 & \\
& Missing & 82.2 & 12.8 & 0.0001 \\
Verbal & Owner occupied & 101.7 & 14.7 & \\
& Rented & 88.9 & 10.8 & \multirow{2}{*}{0.0001} \\
Performance & Missing & 85.9 & 14.3 & \\
& Owner occupied & 99.1 & 13.2 & \\
& Rented & 90.6 & 13.3 & \multirow{2}{*}{0.0001} \\
Reading: & Missing & 81.5 & 17.9 & \\
Rate & & & & \\
& Owner occupied & 115.6 & 21.9 & \\
Accuracy & Rented & 107.1 & 23.9 & \multirow{2}{*}{0.0036} \\
& Missing & 98.0 & 26.1 & \\
Comprehension & Owner occupied & 109.4 & 16.2 & \\
& Rented & 99.8 & 15.4 & \multirow{2}{*}{0.0001} \\
TOMI: & Missing & 93.9 & 18.4 & \\
& Owner occupied & 105.5 & 18.6 & \\
& Rented & 92.5 & 12.0 & \multirow{2}{*}{0.0001} \\
& Missing & 88.7 & 16.6 & \\
& Owner occupied & 2.70 & 2.19 & \\
& Rented & 3.29 & 2.41 & \multirow{2}{*}{0.0001} \\
\hline
\end{tabular}

Table 6 Social status and development: nuimber of social service benefits received (59 none or one social service benefit; 69 more than one; 30 not known)

\begin{tabular}{lllll}
\hline Assessment measure & Category & Mean & $\begin{array}{c}\text { Standard } \\
\text { deviation }\end{array}$ & P value \\
\hline IQ: & One benefit & 102.0 & 14.0 & \\
Full & $>1$ benefit & 89.0 & 11.6 & \\
& Missing & 84.7 & 12.8 & 0.0001 \\
Verbal & One benefit & 103.4 & 15.6 & \\
& $>1$ benefit & 89.3 & 10.7 & \multirow{2}{*}{0.0001} \\
Performance & Missing & 87.2 & 12.7 & \\
& One benefit & 100.0 & 13.3 & \\
& $>1$ benefit & 90.5 & 12.7 & 0.0001 \\
Reading: & Missing & 85.0 & 18.8 & \\
Rate & & & & \\
& One benefit & 118.8 & 23.9 & \\
Accuracy & $>1$ benefit & 105.9 & 21.0 & \\
& Missing & 99.7 & 23.9 & 0.0003 \\
Comprehension & One benefit & 111.6 & 17.1 & \\
& $>1$ benefit & 99.2 & 14.3 & \\
& Missing & 95.9 & 17.4 & 0.0001 \\
TOMI: & One benefit & 107.1 & 18.7 & \\
& $>1$ benefit & 92.7 & 12.5 & \multirow{2}{*}{0.0001} \\
& Missing & 91.0 & 16.7 & \\
& One benefit & 3.08 & 2.41 & \\
& $>1$ benefit & 2.9 & 2.29 & \multirow{2}{*}{0.0001} \\
\hline
\end{tabular}

Table 7 Dependence of IQ and TOMI on birth and social variables

\begin{tabular}{|c|c|c|c|c|c|c|c|c|}
\hline \multirow{2}{*}{$\frac{\text { Predictor (SE) }}{\text { Intercept }}$} & \multicolumn{2}{|l|}{ Full $I Q$} & \multicolumn{2}{|c|}{ Verbal IQ } & \multicolumn{2}{|c|}{ Performance IQ } & \multirow{2}{*}{$\begin{aligned} \text { Full } \\
41.8\end{aligned}$} & \multirow{2}{*}{$\frac{T O M I}{(12.0)}$} \\
\hline & 84.8 & $(5.8)$ & 93.5 & $(6.0)$ & 73.9 & (6.3) & & \\
\hline Birthweight ratio & 22.0 & $(5.9)$ & 14.7 & (6.1) & 25.2 & (6.7) & -14.0 & $(4.4)$ \\
\hline Birthweight (kg) & & & & & & & 7.2 & $(2.9)$ \\
\hline Gestational age & & & & & & & -1.2 & $(0.4)$ \\
\hline More than 1 benefit & -8.8 & $(2.4)$ & -9.1 & $(2.4)$ & & & & \\
\hline Benefit data missing & -9.1 & $(4.3)$ & -8.0 & $(4.4)$ & -6.6 & $(2.5)$ & & \\
\hline Left school by 16 & & & & & & & & \\
\hline years & -8.4 & $(2.8)$ & -10.4 & $(2.9)$ & & & & \\
\hline School data missing & -12.2 & $(4.7)$ & -12.8 & $(4.8)$ & & & & \\
\hline House owner & 5.8 & $(2.3)$ & 6.2 & (2.3) & 5.2 & $(2.5)$ & & \\
\hline House data missing & & & & & -14.3 & (3.7) & 6.6 & $(0.6)$ \\
\hline Variation explained & & $37 \%$ & & $35 \%$ & & $25 \%$ & & $43 \%$ \\
\hline
\end{tabular}

MULTIVARIATE ANALYSIS

As the social variables were likely to be confounded with both SGA and the measures of cognitive ability, a multiple regression was used to examine their joint effects on the 158 children who were tested. The three social variables of housing, maternal education, and benefits, were fitted in addition to the birth characteristics of sex, birthweight, gestational age and birthweight ratio. Not more than $19 \%$ of these social variables were missing.

In the univariate analysis birthweight ratio, but not gestational age, was significantly associated with IQ. Birthweight was associated with performance IQ although not with verbal IQ, and the association persisted with full IQ. In the multivariate analysis the association with birthweight ratio persisted after adjusting for the effects of the social variables. Table 7 shows a 22.0 (standard error 5.9) point IQ difference per unit change in birthweight ratio. Table 2 shows that the birthweight ratio ranged from a minimum of 0.4 to a maximum of 1.5 -that is, a difference of 1.1. Therefore, the estimated effect of the range of growth retardation observed would be $22.0 \times 1.1$-that is, 24 IQ points, after allowing for the effect of the social variables. House ownership, maternal educational level, and number of social service benefits received also adjusted the expected mean IQ. For example, independent of the birthweight ratio, the children from families in receipt of more than one social service benefit, or with missing benefit data had a full IQ that was nine (SE 9) points lower than those from families receiving one or no benefits (table 7). The IQ of children of mothers who left school by the age of 16 was 8.4 (SE 2.8) points lower than those of mothers with further education; and for those with missing school data, the IQ was even lower-12.2 IQ points (SE 4.7). The IQ of children from house-owning families was 5.8 (SE 2.3) points higher than children living in rented accommodation, or those whose data were missing. Overall, $37 \%$ of variation in full IQ was explained by all the variables in the model.

The association with verbal IQ was similar to that for full IQ, although slightly less pronounced; $35 \%$ of the variation could be explained. Performance IQ was slightly more affected by birthweight ratio, but was not associated with maternal education. Missing data on benefits and housing were associated with a drop of 7 and 14 points, respectively, and home owning was associated with a 5 point increase. Overall, a quarter of the variation was explained.

TOMI was associated with birthweight ratio, gestational age, and birthweight, and missing home data. The effects of birthweight ratio and birthweight are substantial and complementary. One unit difference in birthweight ratio almost spanned the range of TOMI, with growth retarded children having poor motor skills. Low birthweight children had better than predicted TOMI than heavier children, and the range 0.6 to $2.0 \mathrm{~kg}$ spanned two thirds of the TOMI score. Overall, nearly half of the variation was explained.

The measures of reading ability showed no appreciable association with birthweight or gestational age, and only comprehension was associated with birthweight ratio, a unit change increasing the expected comprehension by 15 months (table 8). Girls were 14 and 6 months ahead of boys on reading rate and accuracy, respectively, but showed no difference in reading comprehension. Being in receipt of more 


\section{Key points}

- Preterm birth and being small for gestational age differ in their effects on motor and cognitive development

- Cognitive ability, as measured by IQ and reading comprehension, was negatively associated with the degree of fetal growth retardation

- Motor ability was positively associated with gestational age and negatively associated with the degree of fetal growth retardation

- Reading rate and reading accuracy were not associated with either gestational age or the degree of fetal growth retardation, but were socially determined

than one social service benefit was associated with a drop of 12,9 , and 8 months, respectively, in reading rate, accuracy, and comprehension. Maternal schooling and home ownership were not associated with reading rate. Reading accuracy and comprehension dropped 13 and 12 months if the mother had left school early, and a further 12 and 8 months when school data were missing. House ownership gave an expected increase of 7 months in reading comprehension. A quarter of the variation in comprehension was explained. Less of the rate $(17 \%)$ and accuracy $(22 \%)$ variations were attributable to birth or social characteristics.

\section{Discussion}

Previous studies have assessed the association between growth retardation and cognitive ability, but have not examined the effect of growth retardation for a given gestational age. The early United Kingdom study of infants weighing $\leq 1800 \mathrm{~g}$ found that after excluding children with cerebral palsy, growth retarded infants had a lower IQ than normally grown children, but the results were not significant. ${ }^{23}$ The Newcastle study found no difference between those very light for dates and those of short gestation. ${ }^{6}$ The Vancouver study, of infants born in 1959-64, compared preterm infants with those who were small for gestational age within given birthweight groups. ${ }^{24}$ However, to examine the differential effects of SGA and preterm birth, cognitive and motor ability needs to be assessed for levels of growth retardation within a given gestational age. This has not been possible before because infants who were both premature and growth retarded seldom survived.

When assessing whether growth retardation was present, it was customary to use a cutoff such as the 10th centile of weight for gestational age or two standard deviations below the mean, to provide a binary variablethat is, the infant either was or was not growth retarded. Using the ratio of the observed to the expected birthweight for a given gestational age, however, allowed growth retardation to be considered as a continuous variable, thereby permitting greater precision in the analysis of any association of outcome variables with growth retardation. Furthermore, some of the known factors associated with birthweight and gestational age - namely parity of the mother, sex of the infant and plurality of birth-were accounted for when the observed:expected birthweight ratio was determined. Maternal smoking during the pregnancy was not associated with cognitive and motor ability. On the other hand, maternal height, which also affects fetal growth, was not directly allowed for, because of lack of data on this. Nevertheless, the fetal growth effects of both maternal smoking and maternal height were nullified, at least in part, when social variables were included in the multivariate analysis.

The observations reported here showed that SGA, rather than gestational age, was associated with the intellectual ability of the infant even after allowing for the confounding effects of reading ability and social variables. On the other hand, birthweight ratio, birthweight, and gestational age were each independently associated with motor skills, but the social variables showed no such association. This suggests that cognitive and motor abilities have different factors affecting them. Either different aetiological factors are responsible, or the same factor operates at a different stage of fetal development, or perhaps there may be a combination of both.

It is important to acknowledge that this study was confined to infants of under 32 weeks of gestational age. Any growth retardation will have occurred predominantly in the first two trimesters and may differ both in the aetiology and the consequences of growth retardation that take place later on in pregnancy. Very low gestational age was not particularly associated with adverse social circumstances, rather it was maternal illness, such as hypertension and genitourinary tract colonisation and infection, that predisposed to extreme preterm birth. Therefore, it would not be valid to extrapolate the effects of growth retardation observed in this study to infants whose gestational age was greater than 32 weeks. A more extensive study is required to determine the effects of growth retardation occurring later in pregnancy. Even infants $\leq 32$ weeks gestation may not be an homogenous group in relation to mode of delivery and

Table 8 Dependence of reading on birth and social variables

\begin{tabular}{|c|c|c|c|c|c|c|}
\hline \multirow{3}{*}{$\begin{array}{l}\text { Predictor (SE) } \\
\text { Intercept } \\
\text { Birthweight } \\
\quad \text { ratio }\end{array}$} & \multicolumn{2}{|l|}{ Rate } & \multicolumn{2}{|c|}{ Accuracy } & \multicolumn{2}{|c|}{ Comprehension } \\
\hline & 111.8 & (3.3) & 117.8 & (3.4) & 96.7 & $(7.5)$ \\
\hline & 14.1 & $(3.5)$ & 5.6 & $(2.4)$ & 14.6 & $(7.5)$ \\
\hline $\begin{array}{l}\text { More than } 1 \\
\text { benefit }\end{array}$ & -11.5 & $(3.8)$ & -9.1 & $(2.8)$ & -8.1 & $(2.9)$ \\
\hline $\begin{array}{l}\text { Benefit data } \\
\text { missing } \\
\text { Left school by }\end{array}$ & -19.2 & $(4.8)$ & & & & \\
\hline $\begin{array}{l}16 \\
\text { School data }\end{array}$ & & & -12.9 & (3.6) & -11.8 & (3.6) \\
\hline $\begin{array}{l}\text { missing } \\
\text { House owner }\end{array}$ & & & -25.2 & $(4.2)$ & $\begin{array}{r}-19.5 \\
7.4\end{array}$ & $\begin{array}{l}(4.7) \\
(2.7)\end{array}$ \\
\hline $\begin{array}{l}\text { Variation } \\
\text { explained }\end{array}$ & & $17 \%$ & & $22 \%$ & & $26 \%$ \\
\hline
\end{tabular}


growth retardation. Pregnancies at 28-32 weeks gestation are more likely to show growth retardation than those of under 28 weeks because obstetricians are less inclined to curtail pregnancy at under 28 weeks. However, in the data presented here elective caesarean section was only marginally more common in the $28-32$ week gestation group (17.2\% vs $13.3 \%)$ and would not have altered the main findings.

The different effects of SGA and preterm birth observed in this study indicate different mechanisms affecting neurological development. These mechanisms could be the result of different insults acting at the same time or the same insult acting at different stages which produce the different clinical manifestations. Neuronal multiplication and apoptosis, neuronal migration, dendritic arborisation, myelination and synapse formation may be sequential or concomitant. Cognitive ability was associated with growth retardation that occurred before 32 weeks of gestation. The poor TOMI scores, however, were also associated with a short gestational age and could have been due to a disturbance in development or brain injury related to preterm birth and perinatal illness. For preventive purposes, more was known about the risk factors for growth retardation than for preterm birth. ${ }^{10}$ Vigorous management of some of the known causes of growth retardation, such as maternal cigarette smoking, hypertension, and genitourinary infections, may influence cognitive development of the infant but only if the association observed in this study is causal. Similarly, improved motor performance may be possible if the poor TOMI scores associated with preterm birth are attributable to perinatal brain injury or illness.

We thank Clarissa J Stevenson, Rita Angelica, and Hilary Goodman for research assistance. This study was funded by the Department of Health.

1 Dunn HG, Crichton JU, Robertson AM, Tredger EM, McBurney AK. Late prognosis in children of low birthweight. In: Proceedings of the XIIIth International Congress of Paediatrics, Vienna Academy of Medicine. Vienna: Vienna Academy of Medicine, 1971: 33-8.
2 Drillien CM. Aetiology and outcome in low-birthweight infants. Dev Med Child Neurol 1972;14:563-74.

3 Ounsted M, Ounsted C. On fetal growth rate. Clinics in Developmental Medicine No. 46. London: Spastics International Medical Publications, London, 1973.

4 Francis-Williams J, Davies PA. Very low birthweight and later intelligence. Dev Med Child Neurol 1974;16:709-28.

5 Fancourt R, Campbell S, Harvey D, Norman AP. Follow-up study of small-for-dates babies. BMF 1976;291:1435-7.

6 Neligan GA, Kolvin T, Scott DM, Garside RF. Born too soon or born too small. Clinics in Developmental Medicine No. 61. London: Spastics International Medical Publications, 1976.

7 Drillien CM, Thomson AJM, Burgoyne K. Low birthweight children at early school age: a longitudinal study. Dev Med Child Neurol 1980;22:26-47.

8 Parkinson CE, Scrivner R, Groves L, Bunton J, Harvey D. Behavioural differences of school age children who were small for dates babies. Dev Med Child Neurol 1986; 28:498-505.

9 Largo RH, Pfister D, Molinari L, Kundu S, Lipp A, Duc G. Significance of prenatal, perinatal and post natal factors in the development of AGA preterm infants at five to seven years. Dev Med Child Neurol 1989;31:440-56.

10 Kramer MS. Determinants of low birthweight: methodological assessment and meta-analysis. Bull WHO 1987;65:663-737.

11 Thomson AM. Fetal growth and size at birth. In: Barron SL, Thomson AM, eds. Obstetric epidemiology. London: Academic Press, 1983:89-142.

12 Alberman E. Stillbirths and neonatal mortality in England and Wales by birthweight 1953-71. Health Trends 1974; 6:14-17.

13 Staples B, Pharoah POD. Child health statistical review. Arch Dis Child 1994;71:548-54.

14 Scottish Health Service Common Services Agency. Scotland: birthweight, head circumference and length for gestational age. Edinburgh: Scottish Health Service Common Services Agency, 1990.

15 Wechsler D. WISC-R Manual. Windsor: NFER-Nelson, 1976.

16 Neale MD. Neale analysis of reading ability. London: Macmillan Education Ltd, 1966.

17 Stott DH, Moyes FA, Henderson SE. Henderson revision of the Stott-Moyes-Henderson test of motor impairment. Ontario: Brook Educational Publishing Ltd, 1984.

18 Mallows CL. Some comments on $\mathrm{C}_{\mathrm{p}}$. Technometrics 1973; 15:661-75.

19 Miller AJ. Subset selection in regression. London: Chapman and Hall, 1990

20 Scheffe H. A method for judging all contrasts in an analysis of variance. Biometrika 1953;40:87-104

21 Cook RD. Detection of influential observation in linear regression. Technometrics 1977;19:15-18.

22 Flynn JR. Massive IQ gain in 14 nations: what IQ tests really measure. Psychological Bulletin 1987; 101:171-91.

$23 \mathrm{McD}$ onald $\mathrm{AD}$. Children of very low birth weight. A survey of 1128 children with a birth weight of $4 \mathrm{lb}(1800 \mathrm{~g})$ or less. Research Monograph No. 1. London: Medical Education and Information Unit, 1967.

24 Dunn HG, ed. Sequelae of low birthweight: the Vancouver Study. Clinics in Developmental Medicine No. 95/96. Oxford: MacKeith Press, 1986. 